\title{
A study of comparison of tension band wiring versus plating for olecranon fractures
}

\author{
Dhwanil Chandresh Tada, Kushal Nikhil Parikh*, Varun Sanjiv Shah, \\ Bhagirath Durlabhjibhai Goriya
}

Department of Orthopaedics, SMIMER Hospital, Surat, Gujarat, India

Received: 15 January 2020

Revised: 04 April 2020

Accepted: 06 April 2020

\section{*Correspondence:}

Dr. Kushal Nikhil Parikh,

E-mail: kushalparikh@yahoo.com

Copyright: (c) the author(s), publisher and licensee Medip Academy. This is an open-access article distributed under the terms of the Creative Commons Attribution Non-Commercial License, which permits unrestricted non-commercial use, distribution, and reproduction in any medium, provided the original work is properly cited.

\section{ABSTRACT}

Background: Olecranon fractures are one of the common fractures around the elbow, comprising around $37 \%$ of all fractures occurring around the elbow. Olecranon fractures are commonly treated with either plating or tension band wiring. The purpose of current study is to compare the clinical and radiological outcome of tension band wiring and plate fixation in patients operated for olecranon fractures.

Methods: Current study was conducted in a tertiary care center from May 2017-2019. Study compromises of 30 patients operated for olecranon fractures. Clinical and radiological outcome of patients treated with tension band wiring or plating and assessed using the Mayo's elbow score at 6 months follow up.

Results: Out of the 30 patients, 15 were treated with tension band wiring and 15 were treated using open reduction and plating. Out of the 15 operated with tension-band wiring (TBW) K wire on follow up 11 showed excellent score on Mayo elbow score, 2 had good results and 2 had fair results. In patients operated with Plating 12 showed excellent result on follow up and 3 showed good result. No patient had fair or poor score.

Conclusions: Both tension band wiring and plate fixation are effective methods for treatment of olecranon fractures however complications regarding symptomatic metal prominence and superficial infection were higher in patients treated with tension band wiring as compared to plate fixations.

Keywords: Olecranon, TBW, Olecranon-plating

\section{INTRODUCTION}

Olecranon fracture is a common fracture of the upper limb. They constitute around $37 \%$ of all the fractures occurring around the elbow joint. Olecranon fractures affect both the sexes however there is slight male predominance. ${ }^{1}$ Olecranon fractures usually occur by violent injury or by road traffic accident. Olecranon is a part of the elbow joint and hence olecranon fractures cause instability of the joint. $^{2}$

A classification of Olecranon adapted in the clinical practice is the Mayo classification. ${ }^{3}$ Olecranon fractures are intra articular fractures and so they are usually treated operatively in order to restore congruency of the joint surface and avoid post traumatic degeneration of the joint. ${ }^{4}$

Numerous surgical techniques have been described to treat olecranon fractures including tension band wiring, plating, intramedullary screw fixation., ${ }^{4,5}$ Tension band wiring is the most commonly used technique for fixation of simple isolated, displaced fractures of the olecranon. In contrast, pre-contoured anatomical plate fixation is believed to provide better fracture reduction and fixation for comminuted, unstable and oblique fractures. ${ }^{6}$

Aim of the present study was therefore to compare the clinical and radiographic outcome of TBW K-wire and 
pre-contoured locked plate fixation in surgically treated patients with an isolated olecranon fracture.

\section{METHODS}

Present study consisted of 30 cases of fracture of olecranon treated by tension band wiring with Kirshner $(\mathrm{K})$ wire or olecranon plating. The study was carried out at Surat municipal institute of medical education and research, Surat, Gujarat, India from May 2017 to 2019. This is a prospective cohort study to compare the clinical and radiological outcome of tension band wiring with $\mathrm{K}$-wire versus olecranon plating for olecranon fractures.

\section{Inclusion criteria}

Age 18-65 years, limited degree of comminution, closed fractures, skeletally mature patients.

\section{Exclusion criteria}

Other ipsilateral fractures, cerebral palsy, open fractures. Patients of extremes of age and the patients in whom operative risk was great were not taken up for surgery.

On admission each patient was diagnosed using an anteroposterior and lateral elbow radiograph, and the elbow was immobilized in an above elbow slab. The affected limb was kept elevated and appropriate analgesics were given. All pre anesthetic checkup routine investigations like complete blood count, HIV, HBsAg, ECG, and chest X-ray were done.

Out of the total 30 patients, 15 were treated with tension band wiring with $\mathrm{K}$ wire and 15 were treated with plating. Each patient was operated within average of 3 days from admission. Patient were followed up for 6 months' maximum with serial X-rays and clinical examination on each and every follow up. Each patient was evaluated using Mayo elbow score and was documented for the same. Furthermore, complications such a superficial infection and symptomatic metal prominence were also observed in follow ups and were dealt according with antibiotics or removal of implants. Unpaired t test was used to compare the results of the two groups at the end of the study.

\section{RESULTS}

Out of the 30 patients the mean age was years with age range being from 18 years to 59 years. There were 20 males and 10 females thus a 2:1 Male to Female ratio there was male predominance seen. 16 were transverse fractures, 10 oblique and 4 comminuted fracture patterns.

Out of total 30 patients, 15 were operated with TBW k Wire and 15 patients were operated with plating. Out of the 15 operated with tension-band wiring (TBW) K wire on follow up 11 showed excellent score on Mayo elbow score, 2 had good results and 2 had fair results. However, in patients operated with plating 12 showed excellent result on follow up and 3 showed good result. No patient had fair or poor score (Table 1).

Table 1: Mayo elbow score on follow up.

\begin{tabular}{|lll|}
\hline Grading & $\begin{array}{l}\text { No. of TBW } \\
\text { cases }\end{array}$ & $\begin{array}{l}\text { No. of plating } \\
\text { cases }\end{array}$ \\
\hline $\begin{array}{l}\text { Excellent (score } \\
\text { greater than 90) }\end{array}$ & 11 & 12 \\
\hline Good (score 75-89) & 2 & 3 \\
\hline Fair (score 60-74) & 2 & 0 \\
\hline $\begin{array}{l}\text { Poor (score below } \\
\text { 60) }\end{array}$ & - & - \\
\hline
\end{tabular}

Table 2: Complications.

\begin{tabular}{|lll|}
\hline Complications & $\begin{array}{l}\text { No. of TBW } \\
\text { cases }\end{array}$ & $\begin{array}{l}\text { No. of plating } \\
\text { cases }\end{array}$ \\
\hline $\begin{array}{l}\text { Superficial } \\
\text { infection (SI) }\end{array}$ & 3 & 1 \\
\hline $\begin{array}{l}\text { Symptomatic } \\
\text { metal prominence } \\
\text { (SMP) }\end{array}$ & 2 & 1 \\
\hline
\end{tabular}

Table 3: Comparison between outcome analysis of TBW and plating cases.

\begin{tabular}{|c|c|c|c|c|c|}
\hline \multirow[t]{2}{*}{ Variables } & \multicolumn{2}{|l|}{ TBW } & \multicolumn{2}{|c|}{ Plating } & \multirow{2}{*}{ P value } \\
\hline & Mean & SD & Mean & SD & \\
\hline Pain & 41 & 6.86 & 42 & 6.21059 & 0.678929 \\
\hline Motion & 19 & 2.07 & 19.33 & 1.759329 & 0.638432 \\
\hline Stability & 9.33 & 1.75 & 10 & 0 & 0.164318 \\
\hline Function & 24 & 2.80 & 24.33 & 1.759329 & 0.699973 \\
\hline Result & 93.33 & 11.75 & 95.67 & 9.232448 & 0.550513 \\
\hline
\end{tabular}

TBW K-wire patients on follow up 3 patients showed superficial infection and 2 patients showed symptomatic metal prominence. Complications were dealt with accordingly on follow up. Out of the patients operated with plating only 1 patient showed superficial infection and 1 followed up with symptomatic metal prominence (Table 2).

The results were evaluated according to the Mayo elbow performance score. The results obtained in our series were 
excellent in $23(76 \%)$ patients, good in $5(16 \%)$ patients, fair in $2(6.66 \%)$ patients and no poor results.

Also, when we compared TBW K-wire technique with Plating for treatment of olecranon fractures using statistical data and unpaired t test $\mathrm{p}$ value was $>0.05$ which means there is no significant difference in the outcome (Table 3).

\section{DISCUSSION}

The main aim of the treatment of fracture is not only achieving union but to preserve the optimum function of the adjacent soft tissues and joints. In the management of intra articular fractures like of the olecranon, a perfect anatomical reduction of the fragments to obtain articular congruity and rigid fixation of the fragments is of utmost importance, if early movements are to be instituted to prevent complications like traumatic arthritis and joint stiffness.

In our study 15 cases of fracture olecranon were treated with tension band wiring with K-wire and 15 patients were treated by plate fixation. The finding, the end result and various other data will be analysed and compared in the following discussion.

The mean age of our study was around 40 years which was comparable to the study conducted by Schleimann and Rashke, in which average age was around 43 years (Table 4). ${ }^{19}$ There was a male predominance seen in our study with $66.6 \%$ males and $33.3 \%$ females in the study. In a study conducted by Hume and Weiss they showed male predominance with $73 \%$ of males. ${ }^{11}$ Also a study conducted by Schliemann and Rashke showed male predominance (Table 5). ${ }^{19}$

Table 4: Comparison of age.

\begin{tabular}{|c|c|}
\hline Series & $\begin{array}{l}\text { Average } \\
\text { age (years) }\end{array}$ \\
\hline Jiang et al $^{7}$ & 38 \\
\hline Macko et $a^{8}$ & 35.5 \\
\hline Schliemann et al ${ }^{9}$ & 43 \\
\hline Core et al ${ }^{10}$ & 47 \\
\hline Present study & 40 \\
\hline
\end{tabular}

Table 5: Comparison of gender predominance.

\begin{tabular}{|c|c|c|}
\hline Series & $\begin{array}{l}\text { Male } \\
\mathbf{N}(\%)\end{array}$ & $\begin{array}{l}\text { Female } \\
\mathbf{N}(\%)\end{array}$ \\
\hline Jiang et al ${ }^{7}$ & $10(66.66)$ & $5(33.33)$ \\
\hline Hume et al ${ }^{11}$ & $30(73.17)$ & $11(26.82)$ \\
\hline Wolfgang et al $^{12}$ & $27(60)$ & $18(40)$ \\
\hline Schliemann et al ${ }^{9}$ & $13(50)$ & $13(50)$ \\
\hline Present study & $20(66.66)$ & $10(33.33)$ \\
\hline
\end{tabular}

In the present series superficial infection in 3 patients, which was seen in diabetic patients probably due to decreased immunity which was treated with broad spectrum antibiotic. Superficial infection was seen more in patients operated with TBW K-Wire and was less common in patients operated with plating. ${ }^{1,3}$ The symptomatic metal prominence in 3, TBW and plating. ${ }^{1,2}$ Complications in Murphy et al is only symptomatic metal prominence 3 $(6.66 \%){ }^{13}$

Also, when we compared TBW K-wire technique with plating for treatment of olecranon fractures using statistical data and unpaired t test $p$ value was $>0.05$ which means there is no significant difference in the outcome. This result is in accordance with the studies conducted by Schliemann et al and Core et al..$^{9,10}$

However, plating provides a slight advantage over TBW $\mathrm{k}$-wire in terms of less complications and better fixation. Limitations of our study: retrospective design with relatively short follow up (average 6 months). Also, multiple surgeons operated in our institute each with their own operative techniques. Also, the sample size is small compared to other studies. Larger randomized controlled trials with long follow up and functional scoring are required to further clarify these strengths and outcomes of tension band wiring and plate fixation in treatment of olecranon fractures.

\section{CONCLUSION}

From the present study and statistical analysis, we could conclude that both plate/tension band wiring is equally effective for management of olecranon fracture. However, the plate has slight advantage over TBW K-wire in terms of early mobilization and less complications like SMP and SI compared to plating in olecranon fractures.

Considering all the distinct advantages Kirschner wires with tension band wiring for transverse and oblique fractures and olecranon plate for comminuted fractures is the choice of treatment for fractures of the olecranon.

Funding: No funding sources

Conflict of interest: None declared

Ethical approval: The study was approved by the institutional ethics committee

\section{REFERENCES}

1. Ring D. Elbow fractures and dislocations in 'Rockwood and Green Fractures in Adults. Chapter 32. Vol I. $7^{\text {th }}$ edition. In: Bucholz RW, Heckman JD, eds. Lippincott Williams and Wilkins; 2010: 936942.

2. Howard JL, Urist MR. Fracture dislocation of the radious and the ulna at the elbow joint. Clin Orthop. 1958;12:276-84.

3. Veillette CJ, Steinmann SP. Olecranon fractures. Orthopedic Clinics North America. 2008;39(2):22936. 
4. Cooper, Jerald L, Robert DAD. Fracture and Fracture Dislocation about the Elbow. Chapter 33. Operative Orthopaedics. Vol I. $2^{\text {nd }}$ Edn. In: Chapman Michoel W, eds. Philadelphia: J.B. Lippincott Company; 1993: 479-482.

5. Eliot E. Fracture of the olecranon. Surg Clin North Am. 1934;14:487-92.

6. Willams JR. Coronoid, Radial head, Olecranon fractures and Elbow Dislocations' Chapter 3-35. Vol -3. Oxford Text book of Orthopaedics and Trauma. 2002: 1969-1972.

7. Jianc X, Wang M, Huanc Q. Operative treatment of olecranon fracture associated with anterior dislocation of the elbow $[\mathrm{J}]$. Chinese J Orthopaedics. 2000;3.

8. Macko D, Szabo RM. Complications of tension band wiring of olecranon fractures. J Bone Joint Surg. 1985;57:399.

9. Schliemann B, Raschke MJ, Groene P, Weimann A, Wähnert D, Lenschow S, et al. Comparison of tension band wiring and precontoured locking compression plate fixation in Mayo type IIA olecranon fractures. Acta Orthop Belg. 2014;80(1):106-1.

10. Core DMI, Ahn J, Gates S, Jo CH, Maroto M, Sanders D. Comparison of complications, reoperations, and outcomes between tension band wiring and plate fixation in olecranon fractures. $J$ of Orthopaedics Trauma Surg Related Res. 2019;14(1):27.

11. Hume, Mary C, Wiss, Donald A. Olecranon fractures. Clin Orthop. 1992;285:229-35.

12. Wolfgang GA, Burke FR, Bush D, Parenti JO, Perry J, LaFollette BR, et al. Surgical treatment of displaced olecranon fractures by tension band wiring technique. Clinical Orthop Rel Res. 1987;(224):192204.

13. Murphy DF, Greene WB, Damerson TB. Displaced olecranon fractures in adults, Clinical evaluation. Clin Orthop. 1987;224:215-23.

Cite this article as: Tada DC, Parikh KN, Shah VS, Goriya BD. A study of comparison of tension band wiring versus plating for olecranon fractures. Int $\mathbf{J}$ Res Orthop 2020;6:552-5. 